\title{
STUDIES IN DIECKMANN CYCLIZATION AND UTILIZATION OF THE PRODUCTS IN THE SYNTHESIS OF STEROIDS*
}

\author{
BY D. K. BANERJEE \\ (Indian Institute of Science, Bangalore 560012) \\ Received April 11, 1974
}

THE studies on Dieckmann cyclization of various polyesters and utilization of the resulting products for the synthesis of steroids constitute a part of major research activities of our laboratory covering a long period.

Our first attempt consisted in employing the $\beta$-keto ester, 2,3-dicarbethoxy 3 -methylcyclopentanone (1), for the preparation of trans-8-methylbicyclo (3:3:0) octan-1-one (2), the latter being the fused ring system present in the bicyclic keto acid (3) obtained by Wieland ${ }^{1}$ by the degradation of bile acids.<smiles>CCOC(=O)C1C(CCO)C2(C)CCC(=O)C12</smiles>

(1)

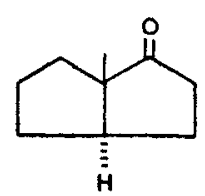

(2)

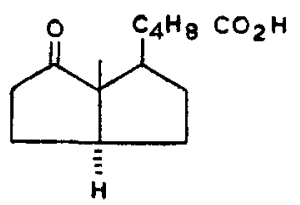

(3)

\section{3)}

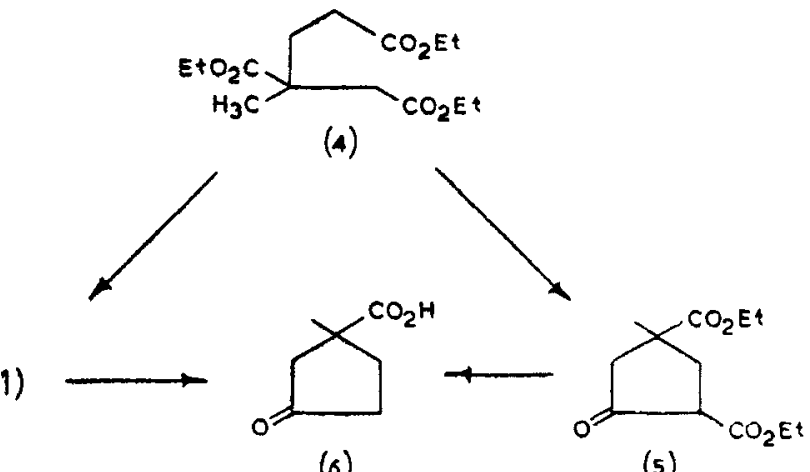

(4)

(1)

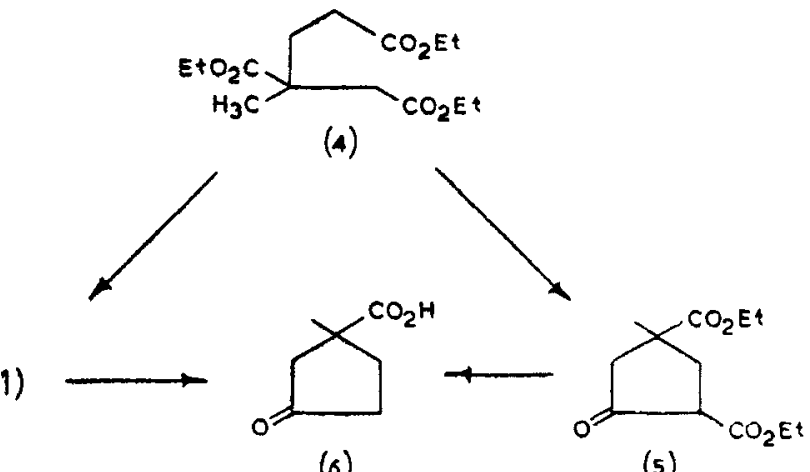

(6)

(5)

* The main sutject-matter of this article was presented at the post-IUPAC meeting held in February, 1972 at the National Chemical Laboratory, Poona-8. India, and later it was presented in greater details with added materials as a serics of lectures at the Kurukshetra University in December 1973. 
Ruzicka $^{2}$ had cyclized ethyl 2-methyl-2-carbethoxyadipate (4) with sodium in benzene and hydrolysed and decarboxylated the resulting crude $\beta$-keto ester to obtain 2-methyl-2-carboxycyclopentanone (6). It may be observed that the triester (4) on cyclization might have given rise to two isomeric $\beta$-keto esters, viz,, 2,3-dicarbethoxy-3-methylcyclopentanone (1) and 2,4-dicarbethoxy-4-methylcyclopentanone (5), and both these $\beta$-keto esters on hydrolysis and decarboxylation would give rise to the keto acid (6). But, Ruzicka did not investigate the structure of the intermediate $\beta$ keto ester.

Later, Baker ${ }^{3}$ oxidized the cyclization product of the triester (4) and claimed to have obtained succinic acid, which, he argued, could only have been obtained from the $\beta$-keto ester (1); the isomeric $\beta$-keto ester (5) would have yielded methylsuccinic acid, the formation of which Baker was unable to detect.

On the basis of Baker's work, we carried ${ }^{4}$ out the sequence of reactions outlined below, using the cyclization product of (4) as the starting material, for the preparation of 8 -methyl( $3: 3: 0)$ octan-1-one (2).

(1)

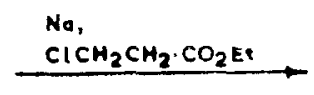

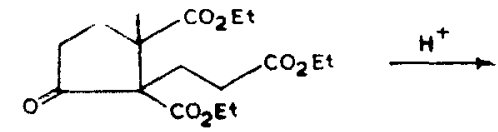

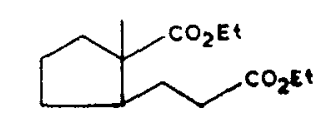

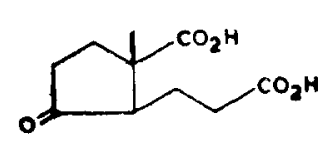
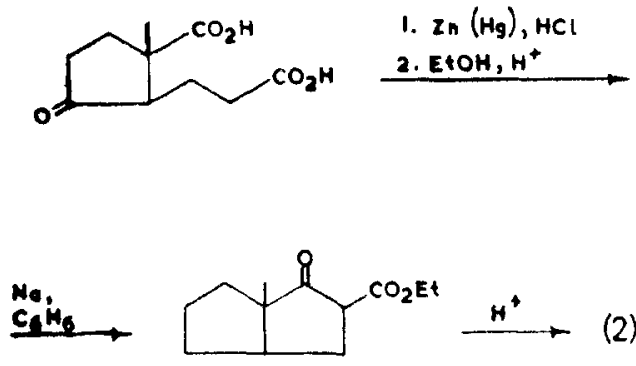

(2)
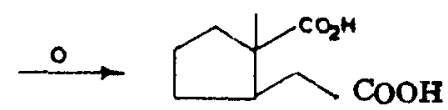

(7)

m.p $126^{\circ}$

Linstead ${ }^{5}$ had earlier prepared both cis- and trans-2-methyl-2-carboxycyclopentaneacetic acids (7), having $\mathrm{mp} .110^{\prime \prime}$ and $139^{\circ}$ respectively. Oxidation of the bicyclic ketone (2) would obviously give the diacid (7), and in order to determine the steric configuration of the bicyclic ketone, obtained by us through the afore-mentioned sequence of reaction, it was oxidised, 
and repeated crystallization of the product furnished crystals with the constant m.p. $126^{\circ}{ }^{4}$ At this stage we had also considered the possibility of the formation of the bicyclic ketone (8), obtainable from the isomeric $\beta$-keto ester (5) through the same series of reactions and the oxidation of which would give rise to the diacid (9). Ruzicka ${ }^{2}$ had. earlier prepared the diacid. (9) by an unambiguous method and described the m.p. as $116-118^{\circ}$. The melting point of the diacid obtained by us $^{4}$ being considerably higher than that described by Ruzicka ${ }^{2}$ for (9), we considered our product to be an eutectic mixture of the cis- and the trans-2-methyl-2-carboxycyclopentaneacetic acids (7).

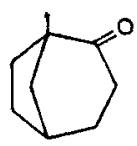

(8)

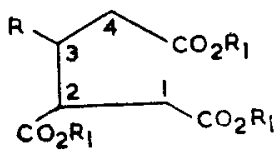

(10)

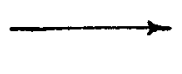

$\begin{array}{ll}\text { a. } R=H & \text { b. } R=\mathrm{R}_{1}=\mathrm{CH}_{3} \\ R_{1}=\mathrm{C}_{2} \mathrm{H}_{5} & \text { c. } \mathrm{R}=\mathrm{CH}_{3} \\ \mathrm{R}_{1} & =\mathrm{C}_{2} \mathrm{H}_{5}\end{array}$

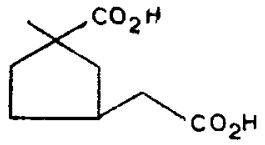

(9)

Chakravarti ${ }^{6}$ in his investigations on the preparation of multi-substituted cyclopentane derivatives proceeded with the cyclization product of the triester (4), initially on the basis of the structure ${ }^{3}$ assigned to it by Baker. Having failed to obtain the desired product, he reinvestigated the structure of the cyclization product on a line identical with that first developed by Ruzicka, ${ }^{7}$ but claimed ${ }^{22}$ by Chakravarti to be his own presumably because he used methyl and ethyl halides as the alkylating species in place of $\beta$-carbethoxyethyl chloride employed by Ruzicka ${ }^{7}$ for determining the structures of the products of cyclization of the lower homologous triester, ethyl 2carbethoxyadipate $(10 a)$, and definitely proved its structure as 2,4-dicarbethoxy-4-methylcyclopentanone (5). He also prepared the diacid (9) by slightly modifying the procedure of Ruzicka, ${ }^{2}$ purified it by crystallization and proved its identity in all respect with the oxidation product of the bicyclic ketone obtained by us, which was thus proved to be 7 -methylbicyclo $(3: 2: 1)$ octan-1-one (8).

As mentioned earlier, Ruzicka et al. ${ }^{7}$ had investigated the cyclization products of ethyl 2-carbethoxyadipate $(10 a)$. These workers separated 
the products on the basis of the difference in their acidities. The more acidic product, which could be extracted with a mixture of equal volumes of saturated aqueous sodium bicarbonate and $2 \mathrm{~N}$ aqueous sodium carbonate, was identified as 2,3-dicarbethoxycyclopentanone (11), while the other isomer, extractable with $2 \mathrm{~N}$ sodium carbonate, was found to be 2,4-dicarbethoxycyclopentanone (12). For determination of the structures of these isomers, each of them was separately alkylated with $\beta$-carbethoxyethyl chloride and then subjected to hydrolysis to obtain two sets of tetra acids (13 and 14) and keto diacids (15 and 16); structures of the former set were proved by direct comparison with authentic specimens prepared by unambiguous methods.

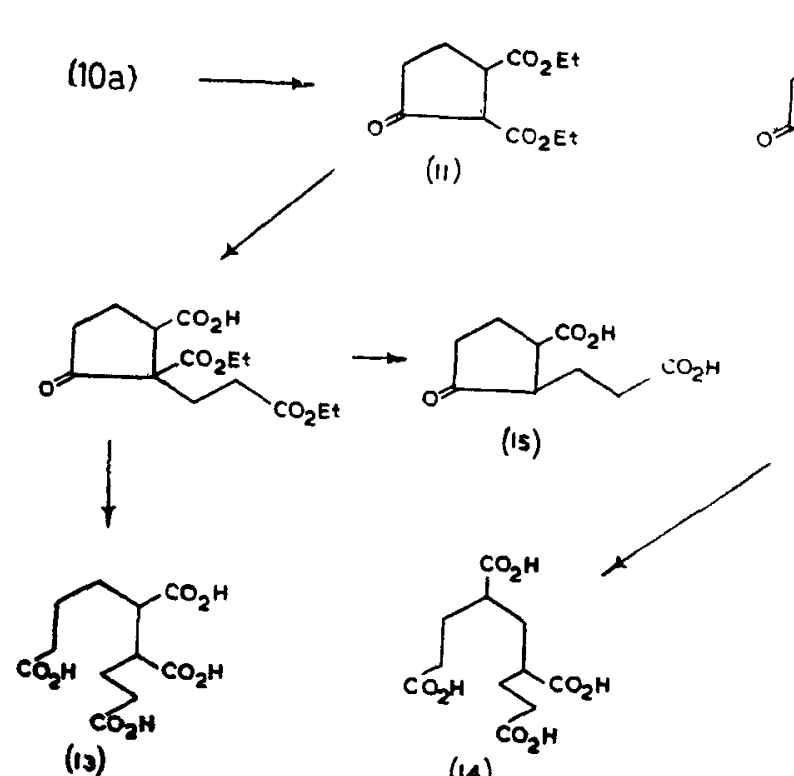

(13)
(14)

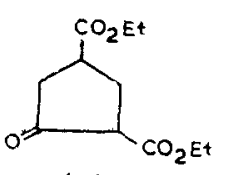

(12)
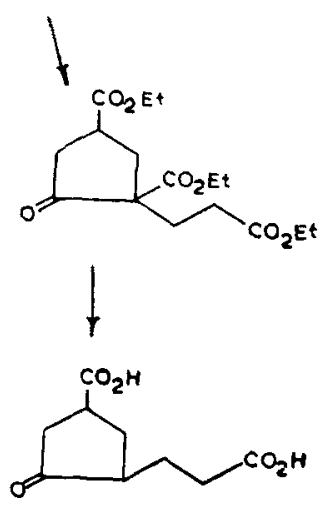

(16)

Ruzicka and co-workers ${ }^{7}$ had cyclized the triester $(10 a)$ using an excess of sodium in different solvents, like benzene, toluene and xylene, and could get the highest yield of the $\beta$-keto ester (11) in xylene. We required the $\beta$ keto ester (11) for the synthesis of a urinary steroid (vide infra). Although we obtained the relatively high yield of the $\beta$-keto ester (11) by following Ruzicka's method, there was formation of a considerable quantity of intractable material. However, using ${ }^{8}$ just a little over a gram atom of sodium and xylene, the formation of undesirable products could be reduced. It appeared to us that the formation of a considerable quantity of the isomer (12) in spite of the greater acidity of the isomer (11) might have been due 
to the hindrance caused by the $\mathrm{C}_{2}$-carbethoxy group to the approach of the $\mathrm{C}_{4}$-carbethoxy group to the $\mathrm{C}_{2}$-methylene anion of the triester $(10 \mathrm{a})$, required for the formation of the carbon-carbon bond in the cyclization and also due to the formation of the insoluble sodium conjugates of the $\beta$-keto esters (11 and 12) in the final step. With the expectation that the thermodynamic equilibrium would be attained in a homogeneous solution leading to the formation of mainly the more acidic $\beta$-keto ester (11), we carried out ${ }^{8}$ the cyclization in an ethanolic solution containing a little more than a molar quantity of sodium ethoxide, and, in spite of the fact that the sodium conjugates were partly insoluble in ethanol, we did obtain an improved yield of the $\beta$-keto ester (11). Presumably, the high yield in xylene was due to the relatively greater solubility of the conjugates in the solvent because of its comparatively high boiling point. Requirement of the $\beta$-keto ester (11) in large quantities for the synthesis of the urinary steroid, led us to study the conversion of the $\beta$-keto ester (12), which had accumulated in considerably quantity during the cyclization of the triester $(10 a)$, to its isomer (11). In view of the equilibrium nature of the Dieckmann reaction, the isomer (12) was treated ${ }^{8}$ with a molar quantity of sodium ethoxide in both refluxing. xylene and ethanol, and mixtures of the two isomers (11 and 12) were obtained in approximately the same proportions as those obtained from the triester $(10 a)$ under the same conditions.
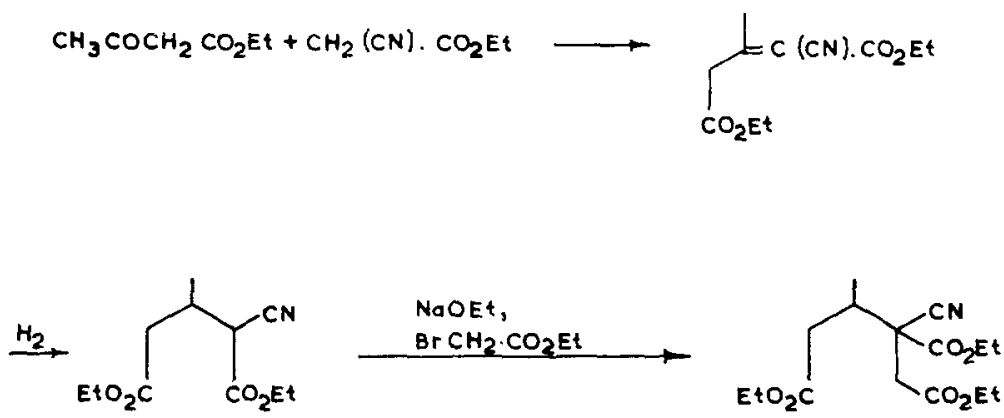

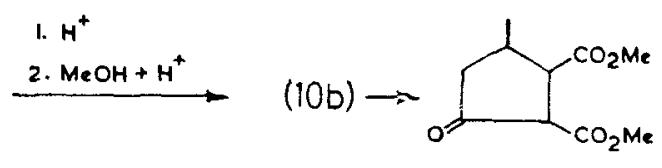

(17)<smiles>CC1C(C(=O)O[Na])CC(=O)C1C(=O)O[Na]</smiles>

(18) 
It appeared to be of interest to study the course of the cyclization if the $\mathrm{C}_{3}$-carbon atom of the triester $(10 \mathrm{a})$ carried a methyl group, because this substituent was expected to cause hindrance to the approach of the $\mathrm{C}_{2}$ carbomethoxy group to the $\mathrm{C}_{4}$-methylene anion of the triester, methyl 2carbomethoxy-3-methyladipate $(10 b)$. Under the circumstances that both $\mathrm{C}_{2^{-}}$and $\mathrm{C}_{3}$-carbon atoms carried substituents of comparable bulks, it was expected that the cyclization might proceed mainly via the anion formed from the more acidic $C_{1}$ methylene which was a part of the succinic ester residue. The triester $(10 c)$ was earlier prepared and cyclized by Hope and Perkin. ${ }^{9}$ They hydrolysed and decarboxylated the cyclized product to 3-carboxy-4methylcyclopentanone without investigating the structure of the intermediate $\beta$-keto ester. The triester $(10 b)$ was prepared ${ }^{10}$ by us by a different and more efficient method, as outlined below. The product of cyclization ${ }^{10}$ of the triester $(10 b)$ with sodium in benzene, which might have given rise to two $\beta$-keto esters (17 and 18), was subjected to Ruzicka's method ${ }^{7}$ of separation, and the $\beta$-keto ester (17) was obtained almost exclusively according to our expectation. The structure of the $\beta$-keto ester was proved ${ }^{10}$ by following the method of Ruzicka ${ }^{7}$ by alkylating it, followed by hydrolysis and decarboxylation of the alkylated product (19) to the cystalline 2,4-dimethyl3-carboxycyclopentanone (20). An authentic specimen of the keto acid (20), for direct comparison, was prepared ${ }^{10}$ as shown below.

(17)

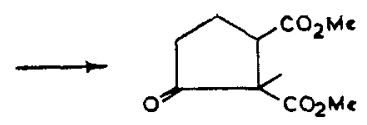

(19)

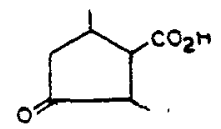

$(20)$

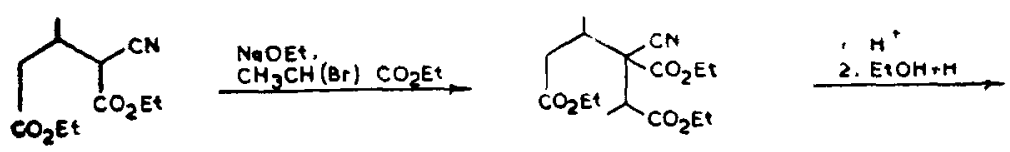

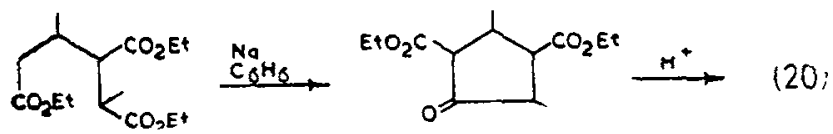

The $\beta$-keto ester (17) has been utilized ${ }^{10}$ for the prepation of oestrone and 19-norsteroid analogues (vide infra).

An enquiry into the Dieckmann cyclization of the higher homologue, ethyl 2-carbethoxypimelate (21), logically arises. However, in this case, the possibility of the formation of three isomeric $\beta$-keto esters $(22,23$ and 
24) exists. The literature records that Perkin et al. ${ }^{11}$ carried out the Dieck. mann cyclization of the triester (21) with sodium in benzene and hydrolysed the product to 3-carboxycyclohexanone $(25 a)$, the structure of which was proved by direct comparison with an authentic specimen prepared from $m$ hydroxybenzoic acid by its catalytic hydrogenation and subsequent oxidation of the 3-carboxycyclohexanol, the reduction product. Perkin thus proved that the $\beta$-keto esters (22 and/or 23) had been formed during the cyclization under the above conditions. Perkin. however, suggested the structure (23) for the product, without providing any experimental proof. Later, Sen and Bagchi, ${ }^{12}$ utilizing the procedure of Ruzicka, ${ }^{7}$ proved it to have the structure (22).<smiles>CCOCCC(CCCSC(C)=O)C(=O)OCC</smiles>

(22)
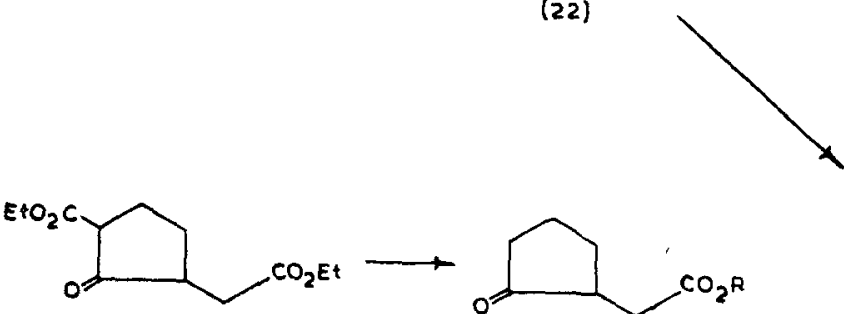

(24)

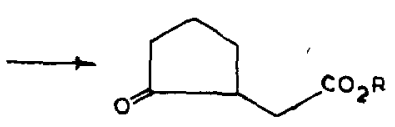

(26)

$$
0, R=\mathrm{H}
$$$$
b, \mathrm{R}=\mathrm{CH}_{3}
$$<smiles>CCOC(=O)C1CCC(C(=O)OCC)C(=O)C1</smiles>

(23)

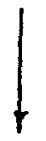<smiles>O=C1CCCC(C(=O)O)C1</smiles>

(25)

Chatierjee et al..$^{13}$ observed that ethyl 2-carbethoxycyclopentanone2 -acetate (27), on treatment with $1 \cdot 1$ mole of sodium ethoxide in ethanol, furnished the $\beta$-keto ester, ethyl 5-carbethoxycyclopentanone-2-acetate (24), the structure of which was proved by hydrolysing it to cyclopentanone-2acetic acid (26a) and comparison with an authentic specimen. Obviously, the $\beta$-keto ester (24) was formed by the cyclization of the triester (21), obtained<smiles>CCOC(=O)CC1(CC)CCCC1=O</smiles>

(27)
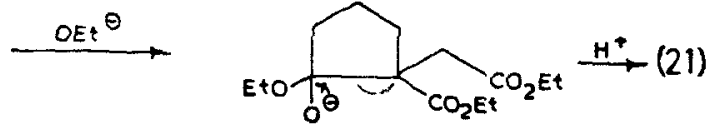
from the keto ester (27) as an intermediate, as suggested by them following Openshaw and Robinson, ${ }^{14}$ by the mechanism shown below. Therefore, the formation of a cyclopentanone derivative (24) under the above conditions in contrast to the formation of the cyclohexanone derivative (22) under the conditions employed by Perkin ${ }^{11}$ posed a problem. We repeated ${ }^{15}$ their experiments ${ }^{11,13}$ and found that both were correct.

Chakravarti ${ }^{16}$ put forward an explanation for the formation of the cyclopentanone ring as shown below, in which he proposed an absurd mode of ring closure after preliminary opening of the ring. Actually, it was a mechanism of Claisen condensation, earlier proposed by Nef, ${ }^{17}$ dressed in terms of electronic theory; Nef's mechanism was criticized by Ingold. ${ }^{18}$

(27)<smiles>CCOCCC1CCCCC1CC(=O)OCC</smiles><smiles>CCOC(=O)CC1CCC(C(=O)OCC)C1(O)OC</smiles>

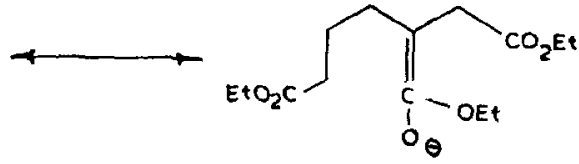

$-(24)+\mathrm{OEt}^{\ominus}$

We carried out a series of experiments which enabled us to offer a solution $^{19}$ to the problem in the light of the work done by Reed and Thornley ${ }^{20}$ and Carrick and Fry ${ }^{21}$ on Dieckmann cyclization. Chakravarti, however, completely overlooked our work ${ }^{19}$ and mentioned in his Acharya P. C. Ray Memorial Lecture ${ }^{22}$ that we were confused by the findings of Perkin ${ }^{11}$ and Chatterjee. ${ }^{13}$

At first we treated the triester (21) with ethanolic sodium ethoxide $(1: 1$ mole) and could obtain the $\beta$-keto ester (24) in a yield comparable to that obtained from the keto ester (27) under the same conditions, thus confirming the possibility of the triester (21) being the intermediate in the conversion of (27) to (24). There was a significant difference observed during the cyclization reaction of (21) under two different conditions. While under the condition of ethanolic sodium ethoxide a homogeneous solution resulted, the sodium conjugate separated out of the benzene solution under Perkin's condition or on the treatment of (21) with sodium ethoxide in benzene. The different modes of cyclization of the triester (21), according to the accepted mechanism of Dieckmann cyclization involving four steps, are shown below. 


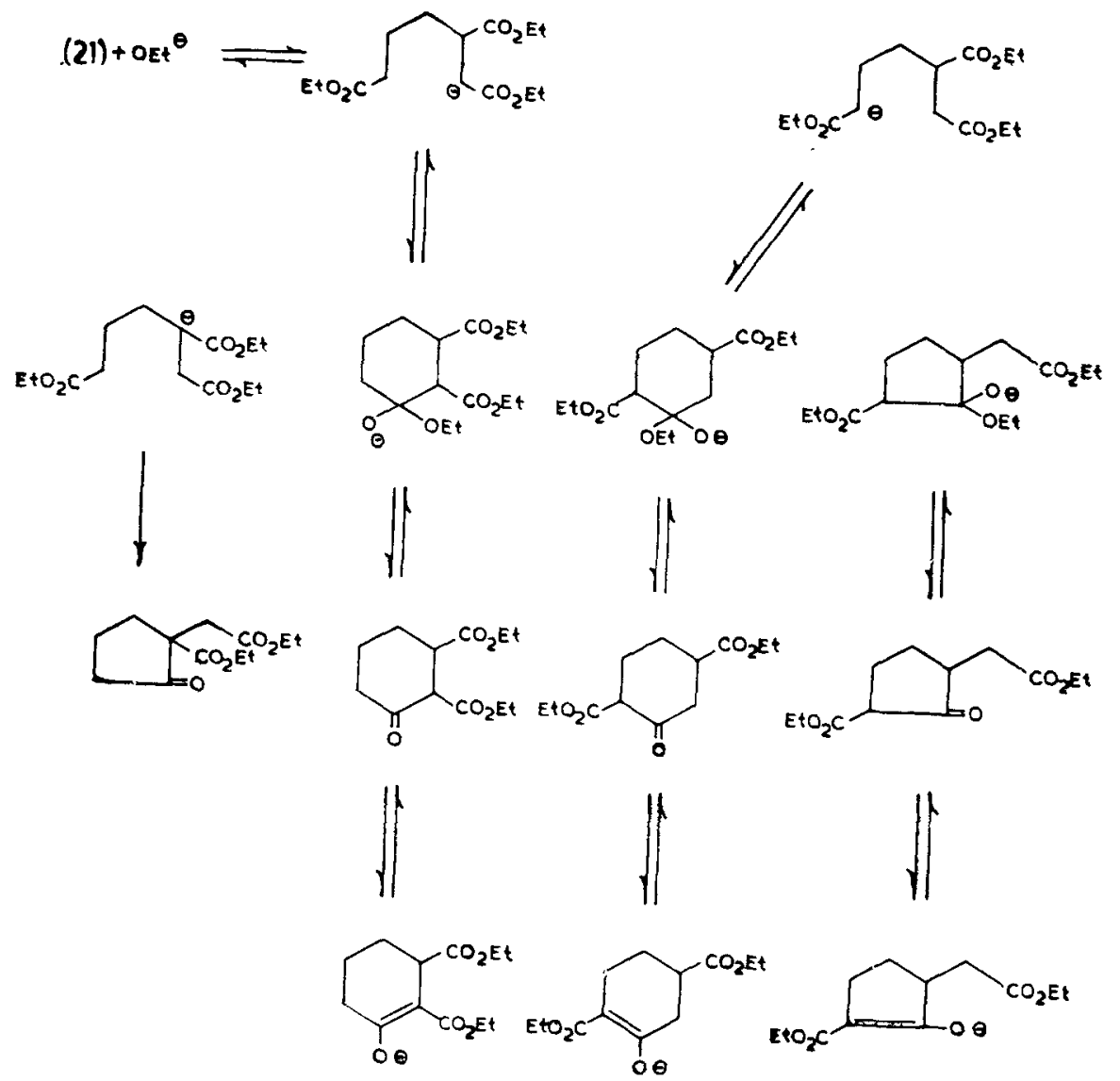

It may be observed that the cyclization involving the $\mathrm{C}_{2}$-methine anion and the $\mathrm{C}_{5}$-carbethoxy group cannot be considered because the product, a cyclopentanone derivative, cannot undergo the stabilizing fourth step by the formation of the enol conjugate of sodium due to the absence of an enolizable hydrogen.

In the Dieckmann cyclization of the triester (21) in a homogeneous solution, i.e. under Chatterjee's condition, the most acidic enolate of the cyclopentane $\beta$-keto ester (24), i.e. the most thermodynamically stable product, should predominate, as all the four steps in this reaction are reversible. Chatterjee's as well as our experiments with the keto ester (27) and the triester (21) respectively confirm this conclusion. In order to provide further proof, we converted the $\beta$-keto ester, 2, 3-dicarbethoxycyclohexanone (22), obtained under Perkin's condition of cyclization, by treatment with 1.1 mole of etha- 
nolic sodium ethoxide to ethyl 5-carbethoxy-cyclopentanone-2-acetate (24) in a yield similar to that obtained from the keto ester (27) or the triester (21).

Reed and Thornley ${ }^{20}$ and Carrick and Fry ${ }^{21}$ in their investigations on Dieckmann cyclization proved that the second step involving carbon-carbon bond formation was the rate determining one. Under the circumstance and also because of low availability of the base at any time when the reaction is carried out with sodium or sodium ethoxide in benzene, the anion formed from the most acidic $\mathrm{C}_{1}$-methylene should predominate in the first step, and the products resulting from the carbon-carbon bond formation in the second step would be immediately removed to go finally out of the reaction as the insoluble metal conjugate. The $\beta$-keto ester under these conditions, therefore, is mainly formed by the interaction between the $\mathrm{C}_{1}$-methylene anion and the $\mathrm{C}_{5}$-carbethoxy group to yield 2,3-dicarbethoxycyclohexanone (22) in accordance with Perkin's ${ }^{11}$ results. To adduce further evidence, we treated an ethanolic solution of the triester (21) with a limited amount $(0.25$ mole) of sodium ethoxide for a short period and could obtain the cyclohexane $\beta$-keto ester (22), but, when the same reaction mixture was refluxed for a prolonged period permitting the equilibrium to be attained, the cyclopentane $\beta$-keto ester (24) was obtained. To clinch the point further, the $\beta$-keto ester (24) was converted to the $\beta$-keto ester (22) by prolonged treatment with sodium ethoxide in refluxing benzene. Obviously, it occurred through the preliminary ring opening, quite likely in very small quantities of the former $\beta$-keto ester, followed by a ring closure under Perkin's conditions.

In all these experiments, the $\beta$-keto esters (22 and 24) were identified by the preparation of derivatives of the keto acids ( $25 a$ and $26 a$ ) respectively, obtained by the hydrolysis and decarboxylation of the former two compounds. This, however, would only be indicative of the presence of major products, and from our study of the Dieckmann cyclization of the triester (21), it was apparent that under both conditions of ring closure the final products could be two different mixtures. That this was actually the case was proved by comparing the IR spectra of the esters, prepared. (diazomethane method) from the crude acids obtained by hydrolysis of the $\beta$-keto esters formed under the two different conditions, with two authentic specimens of keto esters (25b and $26 b$ ). It was found that the composition of the product under Perkin's condition was $80 \%$ of $(25 b)$ and $20 \%$ of $(26 b)$ and that of the product under Chatterjee's condition was $90 \%$ of $(26 b)$ and $10 \%$ of $(25 b)$. 
In view of different modes of cyclization observed in cases of ethyl 2carbethoxyadipate $(10 a)$ and ethyl 2-methyl-2-carbethoxyadipate (4), the manner of the ring closure of ethyl 2-methyl-2-carbethoxypimelate (28) compared to that of ethyl 2-carbethoxy-pimelate (21) appears to be of interest. The added substitution of a methyl group at the $\mathrm{C}_{2}$-carbon of (21), besides reducing the acidity of the $\mathrm{C}_{1}$-methylene group, as pointed out by Chakravarti, ${ }^{23}$ may be expected to sterically hinder the approach of the $C_{1}$-carbethoxyl group to the $\mathrm{C}_{1}$-methylene anion according to the observation of Reed and Thornley. ${ }^{20}$ Consequently, out of the three possible products of cyclization, viz, 2,3-dicarbethoxy-3-methylcyclohexanone (29), 2,5dicarbethoxy-5-methylcyclohexanone (30) and ethyl 5-carbethoxy-2-methylcyclopentanone-2-acetate (31), the last two may be considered to be likely products. We carried ${ }^{15}$ out the cyclization with sodium in benzene and hydrolysed and decarboxylated the resulting product to get only one crystalline keto acid and proved its structure to be 2-methylcyclopentanone-2acetic acid ( $32 a$ ) by direct comparison with an authentic specimen prepared by us by an unambiguous method. ${ }^{15}$ Chakravarti, in his Acharya P. C. Ray Memorial Lecture, ${ }^{22}$ while referring to this work pointed out our inadvertent omission to mention the yield of the keto acid (32a) obtained from (28), but refrained from mentioning that we had studied the ring closure and established the structure of the single crystalline cyclization product.

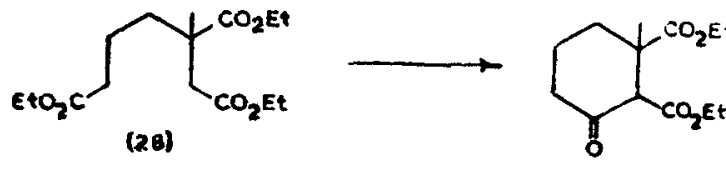

(29)<smiles>CC(=O)C1CCC(C(=O)OCc2ccccc2)C(=O)C1</smiles>

(30)

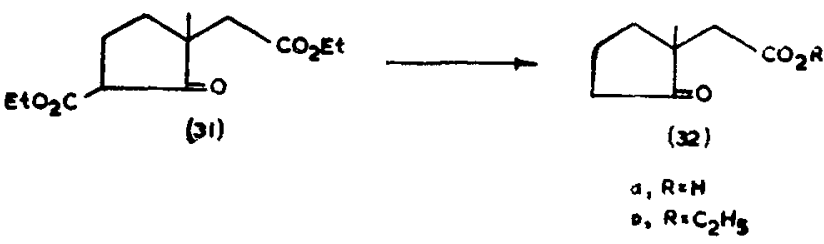

In consideration of preliminary experiments and an early observation of. Robinson ${ }^{24}$ that a suitably 2,3-substituted cyclopentanone derivative might serve as a useful intermediate for the synthesis of steroids and also in view of the result obtained by us in the study of the Dieckmann cyclization 
of ethyl 2-methyl-2-carbethoxypimelate (28), the study of the ring closure of ethyl 2-methyl-2,3-dicarbethoxypimelate (33) appeared worth while. If this tetraester (33) followed the course of ring closure of the triester (28), only ethyl 2-methyl-3,5-dicarbethoxycyclopentanone-2-acetate (36), out of the three possible cyclization products, (34), (35) and (36), should be formed, and this $\beta$-keto ester (36) on hydrolysis and decarboxylation would furnish the required type of cyclopentanone derivative, viz., 2-methyl-3-carboxycyclopentanone-2-acetic acid (37a).<smiles>CCOCCCC(CCC(=O)OCC)C(CCOCC)(OCC)C(CC)OCC</smiles>

(33)<smiles>CCOC(=O)C1CC(C(=O)O[Na])C(=O)CC1(CC)C(=O)OCC</smiles>

(as)<smiles>CCOC(=O)C1CC(C(=O)OCC)C(CCC(=O)O)(CC(=O)O)C1C(=O)O</smiles>

The tetraester (33) was prepared ${ }^{25}$ from ethyl a-acetoglutarate as outlined below.

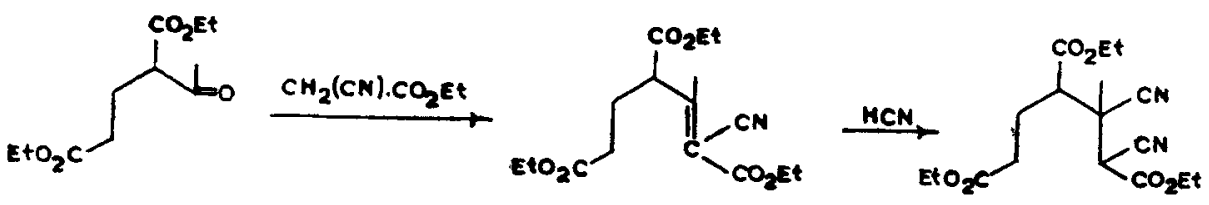

1. $\mathrm{H}^{+}$

2. $\mathrm{E}$ OH, $\mathrm{H}^{+}$

When the tetraester (33) was subjected ${ }^{25}$ to a Dieckmann condensation with sodium in benzene followed by hydrolysis, the crystalline keto dibasic acid (37a) was obtained in good yield. The conversion of (37a) to its stereoisomer through the anhydride (38) followed by hydrolysis gave the compound $(39 a)$. The semicarbazones of diethylesters $(37 b)$ and $(39 b)$, proved to be different from the already known semicarbazone ${ }^{26}$ of the diethyl ester of 
3-methyl-3, 4-dicarboxycyclohexanone, the dibasic acid expected to be formed by the hydrolysis of either (34) or (35). A further proof of the structure of (37) was provided by the conversion of the diethyl ester $(37 \mathrm{~b})$, by reduction of the carbonyl group followed by hydrolysis, to a stereo-isomeric mixture of dibasic acids (40 and 41), previously prepared by Chuang, Ma and Tien. ${ }^{27}$ Presumably, the treatment with refluxing alcoholic hydrogen chloride in presence of zinc amalgam during the reduction experiment was responsible for the conversion of the stereochemically homogeneous (37) into a mixture of stereoisomers of the reduced acids ( 40 and 41 ). We had also prepared ${ }^{25}$ authentic specimens of (40) and (41), for direct comparison, by a new unambiguous method, from $(32 b)$, as shown below. The compound (37) has been utilized for the preparation of steroids belonging to the equilenane and the oestrane groups (vide infra).

(37a)

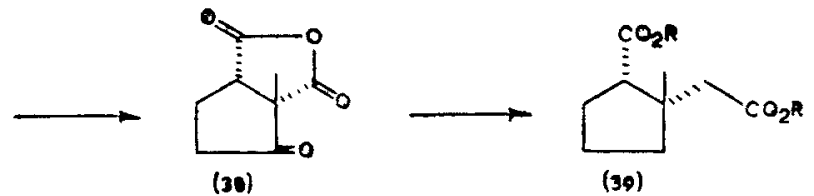

(37b)

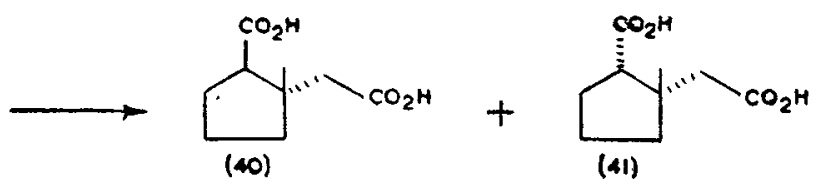

(32b)
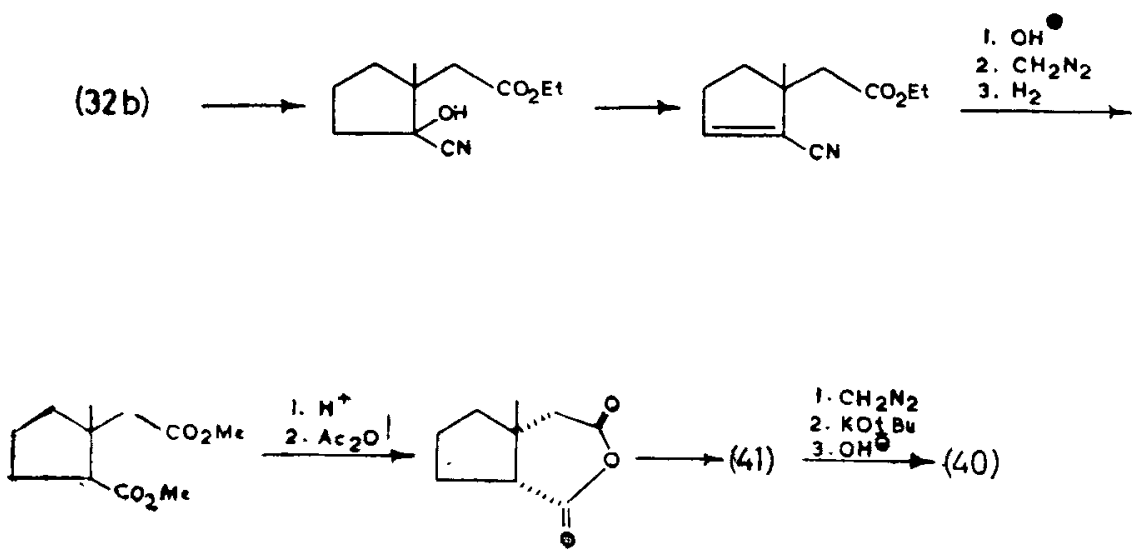
We also envisaged ${ }^{28}$ the preparation of a cyclopentanone derivative, in which the 3-carboxyl group of (37a) has been replaced by a hydroxyl group, by the Dieckmann cyclization of 2-methyl-2-carbethoxy-3-hydroxypimelic ester followed by usual steps. To prepare the afore mentioned hydroxy triester; we condensed ${ }^{28}$ the sodio salt of ethyl methyl $\beta$-ketoadipate (42) with ethyl bromoacetate to obtain ethyl methyl 2-carbethoxy-3-ketopimelate (43). The sodio salt of (43) was alkylated with methyl iodide to afford ethyl methyl 2-methyl-2-carbethoxy-3-ketopimelate (44). The sodium borohydride reduction of the keto triester (44), instead of giving the required hydroxy pimelic ester, furnished a mixture of the lactonic esters (45 and 46), which on cyclization by heating under reflux with potassium $t$-butoxide in $t$-butanol gave a mixture of a lactonic $\beta$-keto ester (47) and a $\beta$-keto lactonic ester (48). That a mixture was obtained in the above two steps was proved by the NMR spectrum of the cyclization product which showed the carbomethoxy group singlet and the triplet and quartet of the carbethoxy group present in (47) and (48) respectively. The possibility of the formation of a mixture of methyl and ethyl esters during the cyclization of either (45) or (46) alone, due to the formation of ethanol or methanol respectively and subsequent trans-<smiles>CCOC(=O)CCC(=O)CCC(=O)OCC</smiles>

(42)

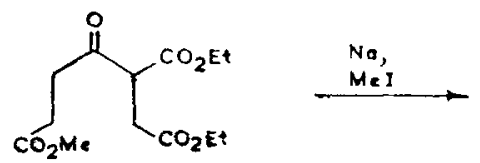

(43)<smiles>CCOC(=O)CC(C(=O)OCC)C(=O)OCCO</smiles>

(44)<smiles>CCOC(=O)CCC1OC2OC(=O)CC12CCON</smiles>

(4s)<smiles>CCOC(C)(CC(=O)O)C1CCC(=O)O1</smiles>

(46)
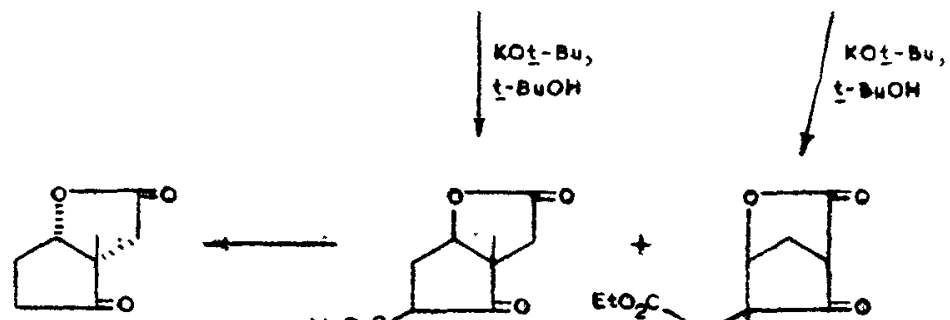

나<smiles>O=C1CC2OC(C(=O)O)(C1)CC2=O</smiles><smiles>CCOC(=O)C[C@]1(C)C(=O)C2CC1OC2=O</smiles>

(4) 
esterification, is unlikely because of the insolubility of potassium conjugates which separate out during the reaction. Acid hydrolysis and decarboxylation of the mixture of (47) and (48) gave a crystalline keto lactone, whose IR, NMR and Mass spectral data were agreeable with the structure (49), along with a very small quantity of an isomeric keto lactone. An unsuccessful attempt ${ }^{28}$ (vide infra) was made to utilize the compound (49) for the synthesis of steroids.

We thought that the minor product could be the cyclohexanone lactone (50) resulting from the hydrolysis of various products that could possibly be formed by ring closure leading to cyclohexanone derivatives. The keto lactone (50) was prepared ${ }^{28}$ by an unambiguous method shown below, but it was found to be different from the minor product. Work is in progress to establish its structure.

Johnson and co-workers ${ }^{29}$ had converted cyclohexan 1,5-dione (51), via a series of reactions, to different isomers of oestrone. We wanted to study the same series of reactions employing 8-methylhydrindan-1,4-dione (52) in place of the dione (51) (vide infra).

For the preparation of the dione (52) we studied ${ }^{30}$ the Dieckmann cyclization of the tetraester (53), which may be considered as methyl 2-methyl-2carbomethoxypimelate substituted at its 1-position with methyl $\beta$-propionate; and the formation of four different cyclization products $(54,55,56$ and 57) is possible. It may be noticed that only the di- $\beta$-keto ester (57) can give rise to the neutral dione (52) by hydrolysis, others giving rise to keto acids.

When the cyclization of (53) was carried out with an excess of sodium hydride in xylene and the resulting product hydrolysed and decarboxylated, the neutral product (52) was obtained in a moderate yield. In order to determine the stereochemistry of (52), as well as to prove its structure, the dione was subjected ${ }^{30}$ to Clemmensen reduction with an equivalent amount of zinc amalgam to obtain cis-8-methylhydrindanone (58) in $13 \%$ yield. Later, ${ }^{31}$ the dione (52) was converted, via its monothioketal (59), to (58) in 55\% overall yield. Although these experiments did not prove the stereochemical homogeneity of the hydrindanone (52), there was no doubt about the product having predominantly the cis configuration. Baggaley ${ }^{32}$ observed that the singlets due to chemical shifts of the angular methyl protons of cisand trans-8-methylhydrindan-1,5-diones appear at $1 \cdot 25$ and $1 \cdot 12 \delta$ respectively in their NMR spectra. The chemical shift due to the angular methyl proton of the dione (52) appeared as only one singlet at $1.15 \delta(100 \mathrm{Mz}){ }^{31}$ proving its stereochemical homogeneity; the value also agreed with that $(1 \cdot 17 \delta)$ recorded by Baggaley ${ }^{32}$ for cis-(52). 
Dieckmann Cyclization and Synthesis of Steroids

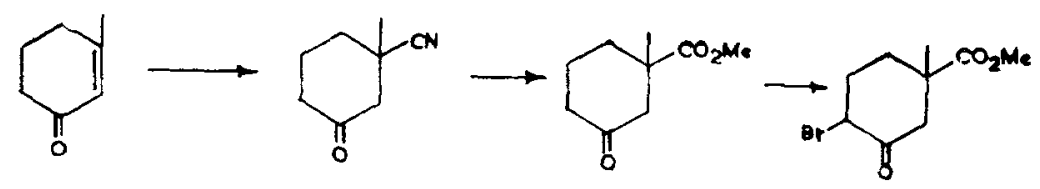<smiles>CCOC(=O)C1CC2(C)CC(=O)CC(C)(C1)C(=O)O2</smiles><smiles>O=C1CCCC2C(=O)CCCC12</smiles>

(51)<smiles>CC12CCCC(=O)C1CCC2=O</smiles>

(52)

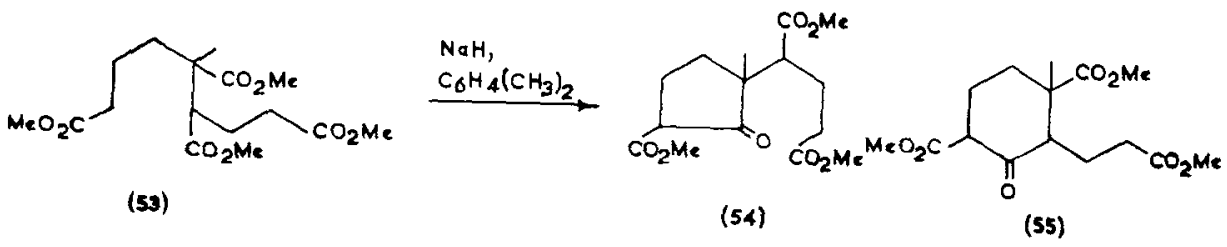<smiles>O=C(O)CCCC1C(=O)C(C(=O)O[Na])CC1C(=O)O[Na]</smiles>

(56)

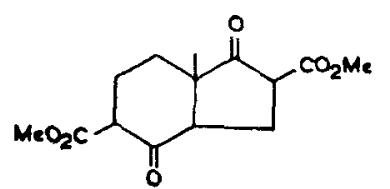

(s7)

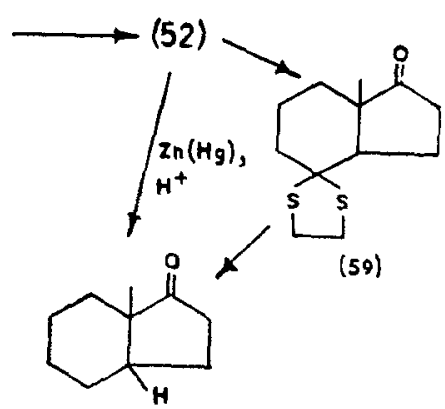

(58)

(53)

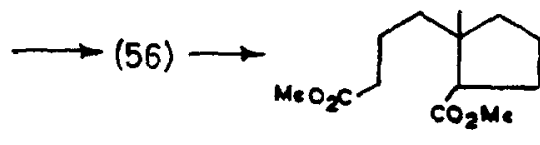

(60)<smiles>CC12CCCC1C(=O)CCC21CCCC1</smiles>

(61) 
The dicyclization of the tetraester (53) must have occurred either by simultaneous ring closures or via the prior formation of either of the monocyclization products (55 or 56 ). In order to determine the priority, if there were one, the compound (53) was treated ${ }^{30}$ with one equivalent of the base $(\mathrm{NaH})$ in benzene and the resulting product was hydrolysed and decarboxylated by treatment with a mineral acid and then subjected to Wolff-Kishner reduction followed by esterification to furnish the diester (60), the Dieckmann cyclization of which followed by the usual hydrolysis step afforded the known 8-methylhydrindan-4-one (61). This proved the formation of the cyclopentane $\beta$-keto ester (56) as the preliminary step in the dicyclization of (53).

Synthesis ${ }^{36}$ of 18-hydroxyoestrone (74), a urinary metabolite, utilizing 2,3dicarbethoxycyclopentanone (11)

The urinary steroid metabolite, known as Kober Chromogen, KC6A, was isolated ${ }^{33}$ by Marrian et al. from the human pregnancy urine. The complete structure of the compound was elucidated by the works ${ }^{34,35}$ of Marrian et al. and was established as 18-hydroxyoestrone (74). Our synthetic investigation ${ }^{36}$ started with the condensation of a mixture of the Mannich base (62) and the vinyl ketone (63), earlier prepared by Smith et al. ${ }^{37}$ for the synthesis of oestrone, with 2,3-dicarbethoxycyclopentanone (11) in the presence of potassium $t$-butoxide in $t$-butanol. The crude condensation product, whose NMR data agreed with the structure (64), was obtained in an excellent yield and was cyclized by treatment with $p$-toluenesulphonic acid in benzene to give the crystalline oestrapentaene diester (65) in fairly good yield. On allowing the diester (65) to absorb one mole of hydrogen by careful hydrogenation in the presence of $5 \% \mathrm{Pd}$-charcoal, the tetraene diester (66) was obtained as a crystalline product. Treatment of (66) with methanolic hydrochloric acid to give the isomeric tetraene diester (67) proved $^{37,38}$ the trans-configuration of the $\mathrm{C} / \mathrm{D}$ ring fusion and the $\beta$-configuration of the 17-carbethoxy group in (66) and (67). Complete hydrogenation of (65) led to the absorption of two moles of hydrogen and formation of the 8-iso-oestratriene diester (68); the configuration has been assigned on the basis of analogy. ${ }^{37}$ Catalytic hydrogenation of (67) furnished the oestratriene diester (69) with the normal steroid configuration. Treatment of (69) with refluxing constant boiling hydrobromic acid (48/) afforded the phenolic diacid (70), which was converted to the phenolic anhydride (71) by pyrolysis. Mesylation of (71) gave the anhydride mesylate (72). Barton et al. ${ }^{39}$ had earlier reported a partial synthesis of $d$-18-hydroxyoestrone (74) 
from $d$-oestrone (73) in which the $d$-isomer of the anhydride mesylate (72) was an intermediate compound. A comparison of the solution IR spectra of our $d l-(72)$ and $d-(72)$ (kindly furnished by Sir Derek Barton) proved their
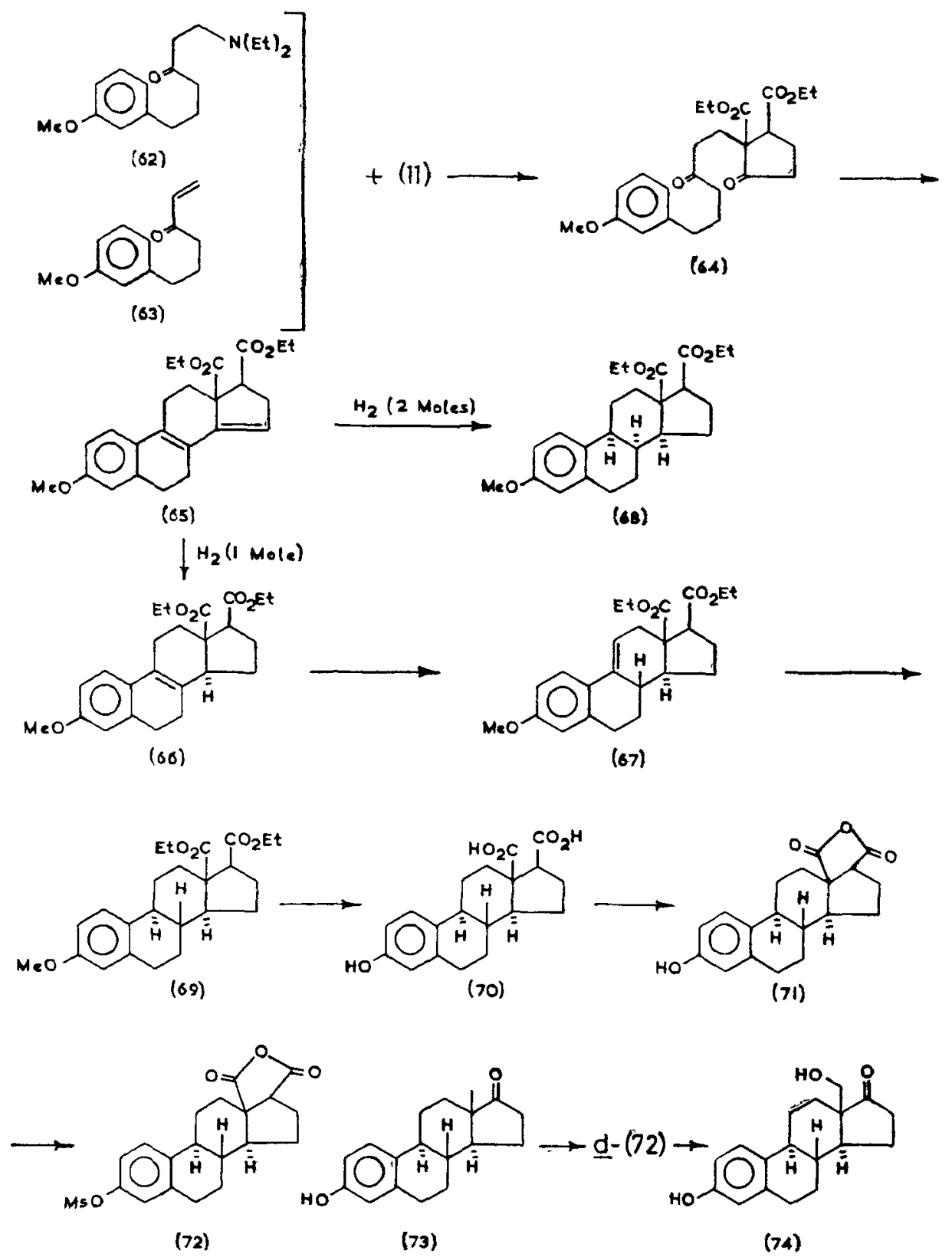
D. K. BANERJEE

identity, and thus a formal synthesis of 18-hydroxyoestrone was achieved by a new route.

Synthesis ${ }^{10}$ of analogues of oestrone and 19-norsteroids utilizing 2,3dicarbethoxy-4-methylcyclopentanone (17)

For this synthetic project, ${ }^{10}$ the mixture of the Mannich base (62) and the vinyl ketone (63) was condensed with the $\beta$-keto ester (17) and the product was put through a part of the same sequence of steps employed in the preceding

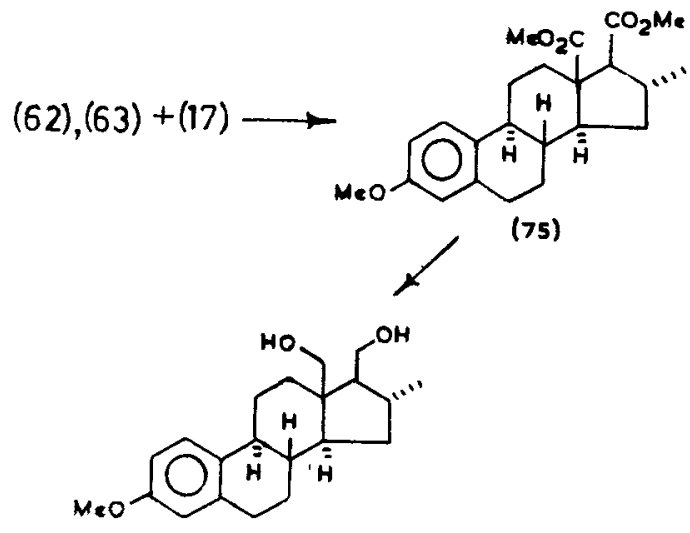

(77)

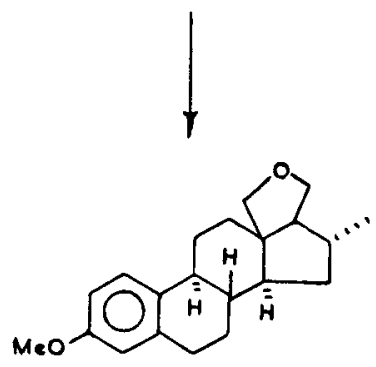

(79)

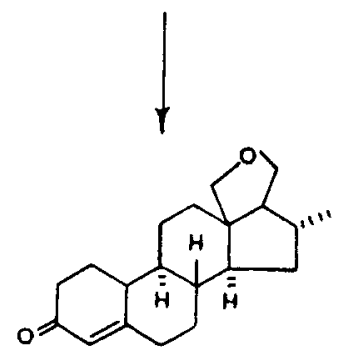

(81)

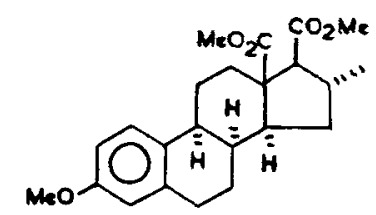

(76)

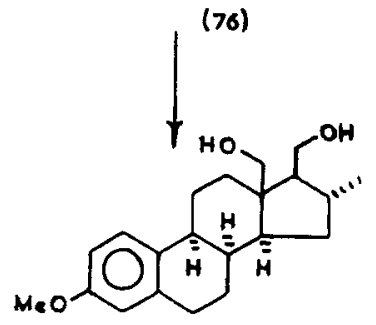

(78)

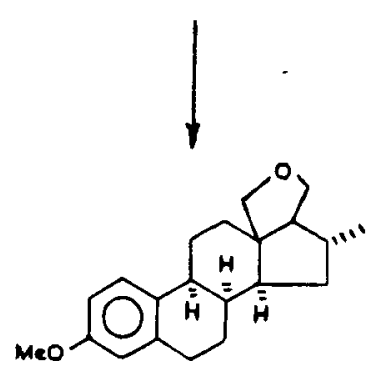

(ec)

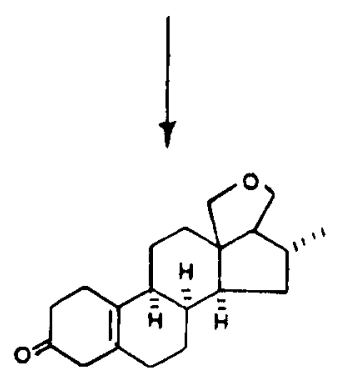

(82) 
synthetic project to obtain the isomeric 16-methyloestratriene diesters (75 and 76); the a-configuration to the methyl group has been assigned on the presumption that it might be comparatively more stable in the quasiequatorial conformation, while configurations of the other groups and ring fusions have been assigned on grounds mentioned in the earlier case. Both, (75) and (76), were reduced with lithium aluminium hydride to the diols (77 and 78); care however was taken to decompse the complex after reduction with water only and not using dilute mineral acid, as under the latter condition the diols would cyclize to oxides, and this very labile conversion provided additional proof in favour of the cis relationship between the ester groups and the $\beta$-configuration of 17-carbethoxy groups in (75) and (76). Diols (77 and 78 ) were converted into the oxides ( 79 and 80 ) by treatment with alcoholic hydrochloric acid, and the latter compounds on Birch reduction furnished $\triangle^{4}-3$-keto-19-nor- (81) and $\triangle^{5(10)}$-3-keto-19-nor-steroids (82) respectively.

Synthesis ${ }^{40}$ of an equilenane molecule, 3-methoxy-17ק-carboxy-1,3,5 (10),6,8-oestrapentaene (87), utilizing the keto diester (37 c)

Condensation $^{40}$ of 2-methoxy-6-lithionaphthalene (83) with the keto diester $(37 c)$ followed by treatment of the crude condensation product with $p$-toluenesulphonic acid in benzene and subsequent saponification furnished the naphthylcyclopentene diacid (84). The point of attachment of the cyclopentane ring to the naphthalene nucleus was proved by oxidizing (84) to 2-methoxy-6-naphthoic acid. Treatment of the diacid (84) with a mixture of phosphorous oxychloride with polyphosphoric acid gave the unsaturated

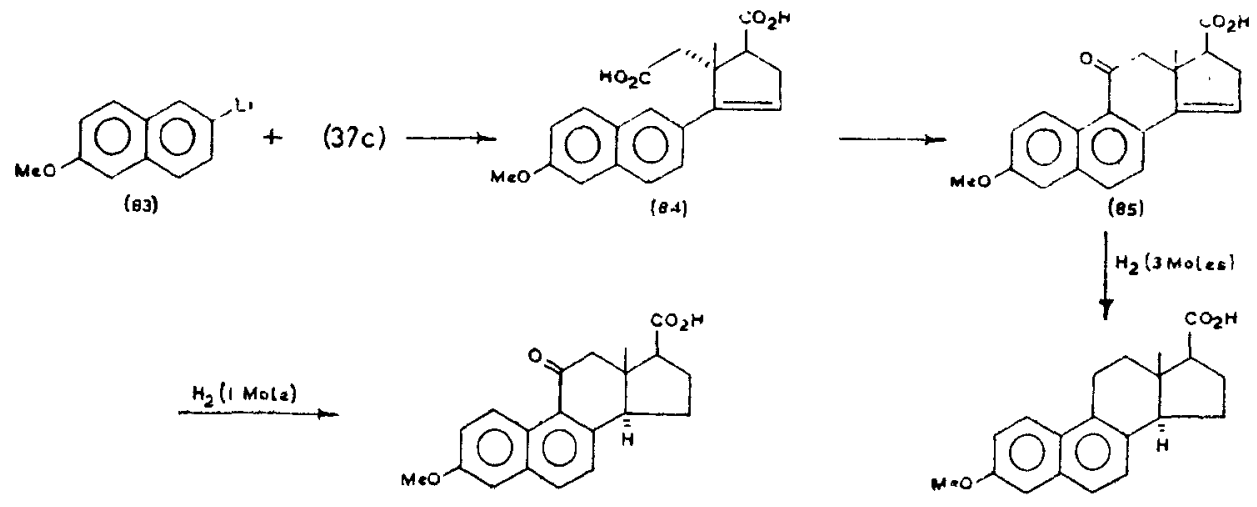

(86)
(87) 
keto acid (85) in good yield. By allowing (85) to absorb one mole of hydrogen by catalytic hydrogenation in the presence of $5 \% \mathrm{Pd}$-charcoal, an excellent yield of the saturated keto aeid (86) was obtained. When the hydrogenation was carried out with $30 \%$ Pd-C catalyst until the uptake of hydrogen stopped, three moles of hydrogen were absorbed to afford 3-methoxy-17-earboxy$1,3,5,(10), 6,8$-oestrapentaene (87). The compound was found to be identical by direct comparison with that synthesized earlier by Banerjee and Johnson et al..$^{41}$ by a different route; the structure and configuration of the previously prepared compound were proved by direct comparison with an authentic specimen prepared ${ }^{41}$ from dl-equilenin methyl ether (88) as shown below.
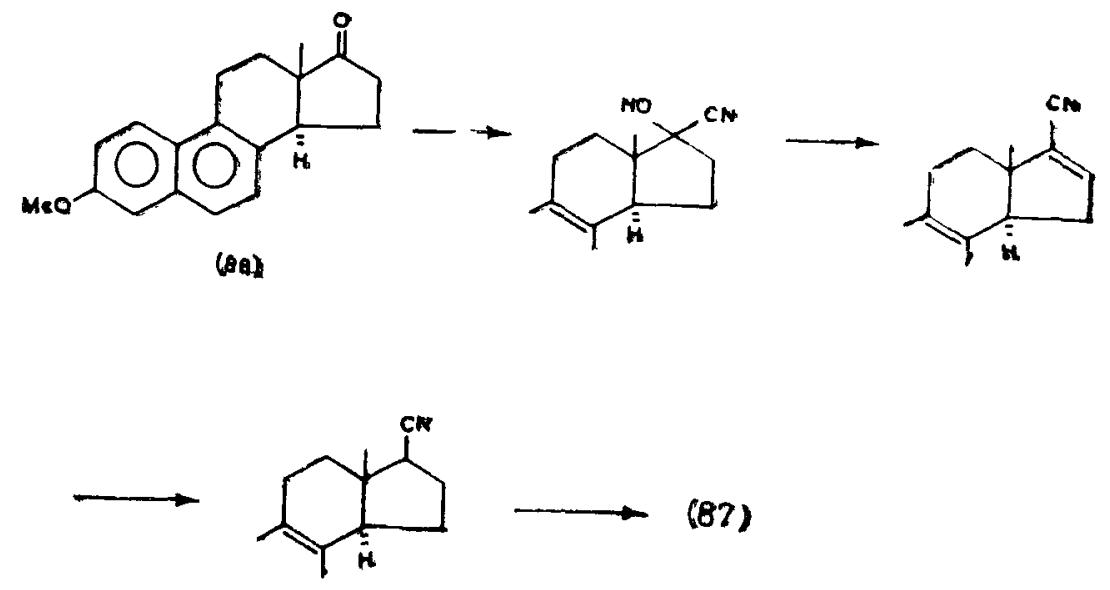

Conversion ${ }^{42}$ of an equilenane to the oestrane: synthesis of 3-methoxy$17 \beta$-carboxy-1,3,5 (10)-oestratriene (91).

The conversion of the saturated keto acid (86), the pieparation of which has been described in the preceding synthetic project, to 3 -methoxy-17 $\beta$-carboxy-1,3,5 (10)-oestratriene (91) constitutes one of the two transformations, ${ }^{42,43}$ of an equilenane derivative to the oestrane reported for the first time.

The keto acid (86) was reduced with sodium and anhydrous ammonia in tetrahydrofuran and ethanol to 3-methoxy-17 $\beta$-carboxy-1,3,5(10), 8oestratetraene (89). The structure of the dihydro compound (89) was proved by the comparison of the NMR spectrum of its methyl ester with that of the methyl ester of the keto acid (86). While the latter compound showed two deshielded C-1 and C-6 protons, doublets (J 10) at $\delta \quad 9 \cdot 33$ and 7.9, presumably due to the proximity of the 11 -keto group in first case and due 


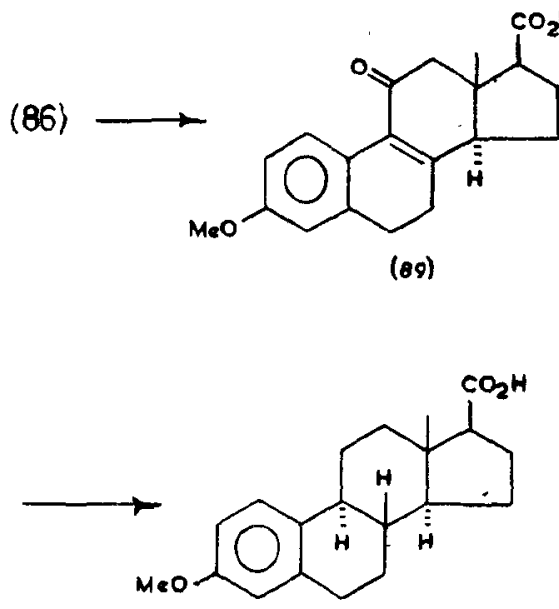

(si)<smiles>COc1ccc2c(c1)CC[C@H]1C3=CC[C@@H](C(=O)O)[C@@]3(C)CC[C@H]21</smiles>

(90)

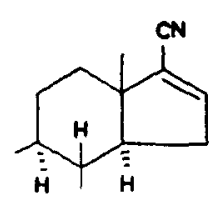

(93)<smiles>COc1ccc2c(c1)CC[C@@H]1[C@@H]2CC[C@]2(C)C(=O)CC[C@@H]12</smiles>

(92)

to the same keto group being in the p-position in the second, the 6,7-dihydro compound (89) showed only one doublet (J 10 ) at $\delta 8.0$ due to the $\mathrm{C}-1$ proton; the difference in the extent of deshielding of the $\mathrm{C}-1$ protons in the two compounds might be due to the difference in their distances, 1.55 and $1.66 \AA$ (Dreiding model), from the 11-keto group. Clemmensen reduction of (89) furnished the 1,3,5 (10),9 (11)-tetraene acid (90), the structure of which was proved by UV, IR and NMR spectra. Catalytic hydrogenation of (90) afforded the triene acid (91), the structure and configuration of which were proved by direct comparison with an authentic specimen prepared from $d l$-oestrone methyl ether (92), via the unsaturated nitrile (93) and the unsaturated acid (94).

An attempt ${ }^{28}$ to utilize the keto lactone (49) for the synthesis of steroids

In an attempt to synthesize equilenane and oestrane derivatives with an oxygen function at the 17-position in place of the carboxy groups as 
present in (87) and (91), 2-methoxy-6-lithio-naphthalene (83) was condensed with the keto lactone (49) followed by dehydration of the crude condensation product to afford a crystalline compound whose spectral and analytical data were agreeable with the structure (95). The extremely poor yield of the product (95) discouraged us to proceed further with the scheme.

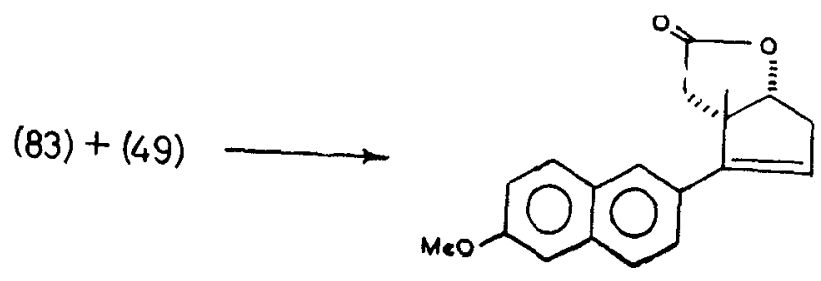

(95)

A study ${ }^{31}$ on the preparation of oestrone and/or its isomer(s) utilizing the hydrindandione (52)

Johnson and co-workers ${ }^{29}$ in their first synthesis of oestrone and its isomers had condensed $m$-methoxyphenylacetylene (96) with the decalindione (51) and the resulting carbinol isomers (97) after hydrogenation, as well as the dehydration product (99) of the hydrogenated material (98), were converted by treatment with aluminium chloride and hydrogen chloride into isomers of the hydrochrysenone (100), which were later converted into oestrone and its isomers by the ring contraction procedure.

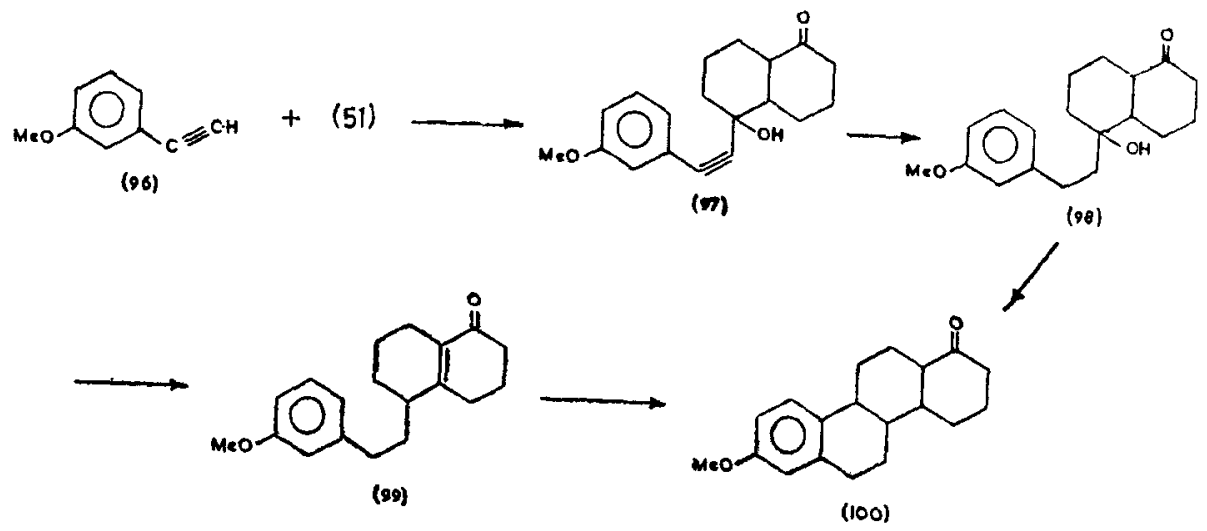

Johnson anticipated the ring closure of the unsaturated ketone (99) to give the hydrochrysenone (100) on the basis of the observation of Nenit$\mathrm{zescu}^{44}$ that benzene and acetylcyclohexane- 1 on treatment with aluminium 
chloride afforded 4-phenyl-1-acetylcyclohexane. It appeared to us that the ring closure might have occurred according to one of the two mechanisms shown below.<smiles>COc1cccc(CCC2CCCC3=C2CCCC3C(C)(C)C)c1</smiles><smiles>COc1cccc(CCC2CCCC3C2CCC[C@@H]3OC(C)(C)C)c1</smiles>

$(100)$

In this mechanism, the repulsion between the strongly polarized positive carbon atom of the carbonyl and the carbonium ion generated by the uptake of a proton by the ethylenic linkage leads to the ring closure at the furthest distance from the polarised carbon.

The ring closure at the angular position via the most stable carbonium ion intermediate (101) is ruled out on the steric ground. However, the formation of the spiro compound (102) is more likely by the second mechanism.<smiles>CCOC1CCCC2=C(OC)C(CCc3cccc(OCC(C)C)c3)CCC=C21</smiles><smiles>COC1=C2CCCC(CCc3cccc(OC)c3)C2CCC1</smiles><smiles>CCC(=O)O</smiles><smiles>COc1cccc2c1CCCC21CCCC2C(=O)CCCC21</smiles> 
In the light of the above considerations, it appeared to be of interest to carry out the sequence of reactions followed by Johnson by replacing 1,5-decalindione (51) with 8-methyl-1, 4-hydrindandione (52); obviously, the second type of mechanism for the ring closure cannot be operative in this case because of the presence of the angular methyl group.

Condensation ${ }^{31}$ of $m$-methoxyphenylacetylene (96) with the dione (52) in presence of potassium $t$-butoxide in $t$-butanol gave a mixture of condensation products, (103) and (104), as evident from its IR bands at 1735 and $1712 \mathrm{~cm}^{-1}$, which could not be separated into its components. In anticipation that the Grignard complex (105), prepared from $\beta$ - $m$-methoxyphenylethyl bromide, might be more specific in attacking the less hindered 4-carbonyl of (52), because of its larger bulk, the dione (52) was condensed with the aforementioned Grignard reagent (105) and the desired condensation product (106), with the carbonyl stretching band at $1735 \mathrm{~cm}^{-1}$, was obtained in $80 \%$ yield on the basis of the recovered dione (52). Dehydration of (106) with formic acid gave the mixture of unsaturated ketones (107), indicated by the presence of a small fraction of one vinyl proton in its NMR spectrum. Attempted cyclization of either (106) or (107) under Johnson's conditions furnished only the unsaturated ketone (108), identified as its semicarbazone<smiles>COc1cccc(CCC2CCCC3C(=O)CCC(CCc4cccc(OC)c4)C2CCC3C(C)C)c1</smiles> 
with the NMR spectrum showing the presence of four aromatic protons. Treatment of (107) with polyphosphoric acid gave a product in a very low yield, whose semicarbazone showed three aromatic protons in the NMR spectrum. The semicarbazone was directly converted into the 2,4-dinitrophenylhydrazone, m.p. 202-204 . Johnson had prepared 2,4-dinitrophenylhydrazones of practically all oestrone methyl ether racemates, and three of those melted close to the above melting point, and he very kindly got the mixture melting points with all three isomers checked and reported that in all cases depressions were recorded. Under the circumstances, we tentatively assign the spiro structure (109) to our product and it appears likely that the second mechanism is operative in Johnson's ring closure of (99) to (100).

\section{ACKNOWLEDGEMENT}

We are indebted to the Council of Scientific and Industrial Research for partly supporting these investigations.

\section{REFERENCES}

1. Wieland, H. and Schlicting, 0 .

Z. Physiol., 1924, 134, 276.

2. Ruzicka, L. .. Ber. Deut. Chem. Ges., 1917, 50, 1362.

3. Baker, J.W.

.. J. Chem. Soc., 1931, p. 1548.

4. Banerjee, D. K.

.. J. Indian Chem. Soc., 1940, 17, 423.

5. Errington, K. D. and

J. Chem. Soc., 1938, p. 668. Linstead, R.P.

6. Chakravarti, R. N. _. J. Indian Chem. Soc., 1943, 20, 173, 189, 243, 247.

7. Ruzicka, L., Borges de Almeida, A. and Brack, A.

8. Sen, P. K. Helv. Chim. Acta, 1 34, 17, 183

.. Ph.D. Thesis, Indian Institute o Science, Bangalore, India, 1973.

9. Hope, E. and

J. Chem. Soc., 1911, p. 762. Perkin, W. H.

10. Banerjee, D. K. and Indian J. Chem., 1971, 9, 1064. Srinivasan, P. R.

11. Dobson, M. E. Ferns, J. J. Chem. Soc., 1909, p. 2010. and Perkin, W. $\mathrm{H}$.

12. Sen, K. and Bagchi, P. .. J. Org. Chem., 1958, 23, 1125.

13. Chatterjee, N. N., Das, J. Indian Chem. Soc., $140,17,161$. B. K. and Barpujari, G. N.

14. Openshaw, H. T. and J. Chem. Soc., 1937, p .941, Robinson, $\mathbf{R}_{\text {: }}$ 
15. Chakravarty, N. K. and J. Indian Chem. Soc., 1946, 23, 377.

Banerjee, D. K.

16. Chakravati, R. N. _ . J. Chem. Soc., 1953, p. 1315.

17. Nef, J. U.

.. Justus Liebigs Ann. Chem., 1897, 292, 202.

18. Ingold, $\mathrm{C} . \mathrm{K}$.

.. Structure and Mechanism in Organic Chemistry, Cornell University Press, Ithaca, N.Y., 1969, p. 1174.

19. Banerjee, D. K., Dutta, Proc. Indian Acad. Sci., 1957, 46 A, 80 ; and Bhagavant, $\mathrm{G}$.

Banerjee, D. K. and .. Ibid., 1960, 52, 165. Bagavant, $\mathbf{G}$.

20. Reed, R. I. and Thornley, M. B.

J. Chem. Soc., 1954, p. 2148.

21. Carrick, W. L. and Fry, A. J. Amer, Chem. Soc., 1955, 77, 4381.

22. Chakıavarti, R, N. .. "Acharya P. C. Ray Memorial Lecture," J. Indian Chem. Soc., 1970, 47, 1025.

23.

.. J. Chem. Soc., 1947, p. 1028.

24. Robinson, R. and Ibid., 1941, p. 378 . Slater, S. N.

25. Banerjee, D.K. and

J. Amer. Chem. Soc., 1952, 74, 1318. Das Gupta, S. K.

26. Mukharji, P.C.

.. J. Indian Chem. Soc., 1948, 25, 365.

27. Chaung, C., Ma, C. and Ber. Deut. Chem. Ges., 1935, 68, 1946. Tien, $\mathbf{Y}$.

28. Surendranath, $V$. .. Ph.D. Thesis, Indian Institute of Science, Bangalore, India, 1972.

29. Johnson, W. S., Banerjee,

J. Amer. Chem. Soc., 1952, 74, 2832. D. K., Schneider, W. P., Gutsche, C. D., Shellberg, W. E. and Chinn, L.J.

30. Banerjee, D. K. and Ibid., 1950, 72, 1931. Shafer, P. R.

31. Venkataramu, S. D. . Ph.D. Thesis, Indian Institute of Science, Bangalore. India 1972.

32. Baggaley, K. H., Brooks, S. G., Green, J. and Redman, B. T.

33. Marrian, G. F., Watson, Biochem. J., 1957, 65, 12. E. J. D. and Panattoni, M.

34. Loke, K. H., Marrian, G. F., Johnson, W.S., Meyer, W. L. and Cameron, D. D.

J. Chem. Soc., C, 1971, pp. 2671, 2678.

Biachim. Biophys. Acta, 1958, 28, 214. 
35. Loke, K. H., Marrian, G. F. Biochem. J., 1959, 71, 43.

Watson, E. J. D.

36. Banerjee, D. K., Unpublished Work.

Venkataramu S. D.

and Sen, P. K.

37. Douglas, G. H., Graves, J. Chem. Soc., 1963, p. 5072.

J. M. H., Hartley, D.

Hughes, G. A. McLoughlin,

B. J., Siddall, J. and

Smith, $H$.

38. Cole, J. E., Jun., Ibid., 1962, p. 244.

Johnson, W. S., Robins, P. A.

and Walker, $\mathrm{J}$.

39. Baldwin, J. E., Barton, Ibid., 1968, C, 2283.

D. H. R., Dainis, I. and

Pereira, J. L.C.

40. Banerjee, D. K., Mahishi, N. and Deva-

prabhakara, $\mathrm{D}$.

E. J., Ramani, G. and Deva-

prabhakara, $D$.

41. Banerjee, D. K., Khastgir, Tetrahedron Lett., 1961, p. 76,

H. N., Dutta, J., Jacob, E. J., Johnson,

W. S., Allen, C. F.,

Bhattacharyya, B. K.,

Collins, J. C.,

Jun., McCloskey, A. L.,

Tsatsos, W.T.,

Vredenburgh, W. A. and

Williamson, K.L.

42. Jacob, E. J. and

Steroids, 1970, p. 733.

Mahishi, N.

43. Birch, A. J. and

Subba Rao, G.S.R.

Tetrahedron Lett., 1968, p. 479 ;

Steroids, 1970, p. 561. 